\title{
The cost of medication and the cost of treatment are not the same thing for multiple sclerosis
}

\author{
0 custo do medicamento e o custo do tratamento \\ não são a mesma coisa para esclerose múltipla
}

Yara Dadalti Fragoso

\section{Head of the Department of Neurology, Universidade Metropolitana de Santos, São Paulo (SP), Brazil; \\ Senior Neuroscientist, University of Aberdeen, Scotland. \\ Correspondence \\ Yara Dadalti Fragoso \\ Rua da Constituição 374 \\ 11015-470 Santos SP - Brasil \\ E-mail:yara@bsnet.com.br}

\section{Conflict of interest}

There is no conflict of interest to declare.

Received 01 June 2013 Accepted 10 June 2013

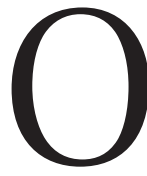
nly two decades ago, patients with multiple sclerosis (MS) had no specific treatment and were managed with symptom control, physiotherapy, psychosocial support and, if necessary, disability aids. The arrival of different formulations of interferon beta and alternatively, glatiramer acetate in the 1990s brought about a new era in MS treatment. Patients and doctors have now become familiarized with these two classes of drugs and millions of patients have used them worldwide. More recently, two new drugs entered the market as potentially more effective medications: natalizumab and fingolimod. Their higher efficacy seems to give room for adverse events of greater severity, but the medical community is slowly learning how to manage these new treatments as well. Previous immunosuppressive drugs with potential life-threatening side effects and low specificity for MS treatment have now been abandoned in more developed countries, and also in Brazil.

All available drugs for MS treatment comprise sophisticated molecules, and therefore, they have a high cost of production and commercialization. Most patients would not be able to afford these treatments in any country worldwide, and reimbursements by different governments in different countries are the reality for the majority of the population in need of these medications. Patients, doctors, and governments are aware that MS treatment is expensive. However, the cost of a disease is not equal to the cost of its medications. There are personal and professional costs in a potentially disabling disease like MS that may render the patient incapacitated for work and thus dependent on caregivers. If a patient is not given treatment in the early stages of the disease, he/she will more rapidly reach a degenerative phase of MS that brings with it a variety of expenses and a severe personal and social burden. Inability to walk and control sphincters, cognitive dysfunction, and visual impairment are costly conditions for healthcare services and a profound burden on patients and their relatives.

All treatments for MS aim at reducing the relapse rate and not at providing a cure. Therefore, the cost of treating relapses must also be considered into the equation. The cost of nonadherence is an added complication, as are the countless examinations that the patient will go through while on MS treatment. Several examinations are required for diagnosing MS, with differential diagnoses in the early stages of the disease and during the follow-up stages. Blood tests, imaging examinations, consultations, and treatments with other specialties (ophthalmologists and psychiatrists, for example), together with their prescriptions, also add to the final bill. When new drugs come into the market, the cost of equally new adverse events must be taken into consideration. Time off work and early retirement may be the rule when the working environment is not prepared for individuals with MS. There are costs that are not even visible in the healthcare system, such as adaptation of a shower cubicle in the house of a patient whose neurological functions begin to deteriorate.

The cost of treating MS is high, but so is the cost of not treating it. The difference is that the cost of treatment is felt in the more inflammatory, initial phase of the disease, while the cost of not treating it, is felt in the more degenerative, later stage of MS. With so many drugs 
on the market now, how can doctors or governments decide which one is the most cost-effective?

Modeling the cost of a disease is never easy, but somehow it seems particularly difficult for MS since the disease has so many parameters to be analyzed. A recent systematic review on this subject ${ }^{1}$ showed that different authors use different models for assessing cost-effectiveness. In fact, the differences are so wide that some models ${ }^{2}$ consider two years and others ${ }^{3}$ ten years of MS treatment for their cost estimates. Furthermore, all countries in which this matter has been studied have produced different results regarding cost-effectiveness because the drugs have different prices in different countries, as do the examinations, other consultations and treatments, and the disability aids that come with the disease. Lessons from pharmacoeconomics cannot be transplanted from one country to another; each country will have to perform its own studies in order to understand which strategy is best for treating MS. Simply introducing a "cheaper" medication does not mean better cost-effectiveness in a chronic and complex disease like MS. The benefits (or lack) of cheaper generic drugs or biosimilars may not be understood until ten years have passed, at which time it is too late for the patient and for the healthcare system.

The subject raised by Romano et al. $^{4}$ is of paramount importance in our continent. We struggle with a variety of problems in Latin American healthcare systems. Those with the power to make decisions regarding MS treatments need to be aware of the cost-effectiveness of present drugs, new drugs, biosimilars, complex molecules, etc. Without the aid of pharmacoeconomic analyses, we may never achieve the best cost-effective treatment for any disease. The examples put forth by researchers, who have already started studying and publishing on this subject, have to be followed by the rest of us.

\section{References}

1. Thompson JP, Abdolahi A, Noyes K. Modeling the cost effectiveness of disease-modifying treatments for multiple sclerosis: issues to consider. Pharmacoeconomics 2013. [Epub ahead of print].

2. Goldberg LD, Edwards NC, Fincher C, Doan QV, Al-Sabbagh A, Meletiche DM. Comparing the cost-effectiveness of disease-modifying drugs for the first-line treatment of relapsing-remitting multiple sclerosis.J Manag Care Pharm. 2009;15:543-555.
3

Prosser LA, Kuntz KM, Bar-Or A, Weinstein MC. Cost-effectiveness of interferon beta-1a, interferon beta-1b, and glatiramer acetate in newly diagnosed non-primary progressive multiple sclerosis. Value Health. 2004;7:554-568.

4. Romano M, Machnicki G, Rojas JI, Frider N, Correale J. There is much to be learned about multiple sclerosis costs in Latin America. Arq Neuropsiquiatr. 2013;71(8):549-555. 